\title{
A cumulative dose comparison between salbutamol and fenoterol metered dose aerosols in asthmatic patients
}

\author{
David Bellamy and Andrea Penketh
}

Brompton Hospital, London SW3, UK.

\begin{abstract}
Summary: The potency and side effects of salbutamol and fenoterol inhalers have been compared in 8 asthmatic patients using a dose response curve. There was no significant difference in the absolute or percentage increase in $\mathrm{FEV}_{1}$ with the two treatments, but fenoterol caused a significantly greater $(P<0.01)$ increase in heart rate than did salbutamol. A greater degree of bronchodilatation was observed with increased doses and we suggest that regular higher doses may provide better bronchodilatation and control of asthma in selected patients.
\end{abstract}

\section{Introduction}

Inhaled aerosol beta-2 agonists are known to be efficacious in the treatment of asthma and chronic obstructive bronchitis. Previous studies ${ }^{1-3}$ have suggested that the effect of most beta-agonist inhalers, in the manufacturers' recommended dose, is similar. It has also been claimed ${ }^{3}$ that fenoterol may have a slightly longer duration of action, but this will depend on doses employed and relative potency. When this was taken into account fenoterol was not found to have a longer duration of action than terbutaline. ${ }^{4}$

The present study sets out to compare the potency of salbutamol and fenoterol using a cumulative dose response and to examine the relative side effects of both drugs particularly in relation to unwanted cardiac stimulation. Currently there is a trend towards using higher doses of inhaler bronchodilators, particularly in the prevention of early morning dipping. ${ }^{5,6}$ By constructing cumulative dose response curves the relationship between an optimal bronchodilator dose and its effect on heart rate can be demonstrated.

\section{Materials and methods}

Eight asthmatic patients ( 6 female, 2 male) with mean age of 33 years (range 18 to 51 years) took part in the study. They all previously demonstrated a better than $20 \%$ increase in forced expired volume in 1 second $\left(\mathrm{FEV}_{1}\right)$ after 2 puffs of salbutamol from a metered dose inhaler. At the time of the study their asthma had

Correspondence: D. Bellamy, M.B., B.S., M.R.C.P., 31 Silverdale Road, Burgess Hill, Sussex RH150ED, UK. Accepted: 25 November 1986 been stable for at least 1 month and there had been no change in medication during this period. Only one of the patients was taking oral corticosteroids (prednisolone $2.5 \mathrm{mg} / \mathrm{day}$ ), the remainder being treated with either a beta-2 agonist inhaler alone or in combination with inhaled beclomethasone dipropionate.

Patients were studied on 2 separate days, at the same time each morning, within the space of 1 week. All bronchodilator therapy was stopped for at least 12 hours before each study period. For inclusion in the study, baseline FEV, had to be less than $75 \%$ of the predicted value.

The baseline $\mathrm{FEV}_{1} \mathrm{~s}$ on the 2 study days were within $10 \%$ of each other. All patients were experienced in the use of metered dose inhalers and a bellows spirometer (Vitalograph). On each study day, 3 baseline readings of FEV ${ }_{1}$ and heart rate (measured over 30 seconds at the radial pulse) were taken and the patients then given, non-blind (as the tastes of the aerosols are quite characteristic), either 2 puffs of salbutamol or fenoterol in randomized order. $\mathrm{FEV}_{1}$ and heart rate were recorded at 5, 10, 15 and 30 minutes after inhalation. A further 4 puffs of the aerosol were administered and a similar set of measurements made. Finally 6 puffs of the aerosol were given and readings taken for 60 minutes. The patients were asked to report any side effects. Statistical analysis was by Student's $t$ test for paired data.

\section{Results}

The mean changè in $\mathrm{FEV}_{1}$ and heart rate (Figure 1) are expressed as a percentage of the best baseline 
values. Both drugs are shown to be active bronchodilators. The percentage change in $\mathrm{FEV}_{1}$ after 2 puffs of either inhaler is almost identical. With higher doses, fenoterol appears to have a slightly greater activity, but the differences did not reach statistical significance. The absolute increases in $\mathrm{FEV}_{1}$ for salbutamol at cumulative doses of 2, 6 and 12 puffs were 0.45 litres, 0.54 litres and 0.71 litres respectively and for fenoterol, 0.48 litres, 0.78 litres and 0.86 litres. Analysis of these values likewise showed no significant differences between the two treatments.

Salbutamol had relatively little effect on heart rate even after the highest dose (absolute mean increase of 12 beats/minute) but fenoterol had much more

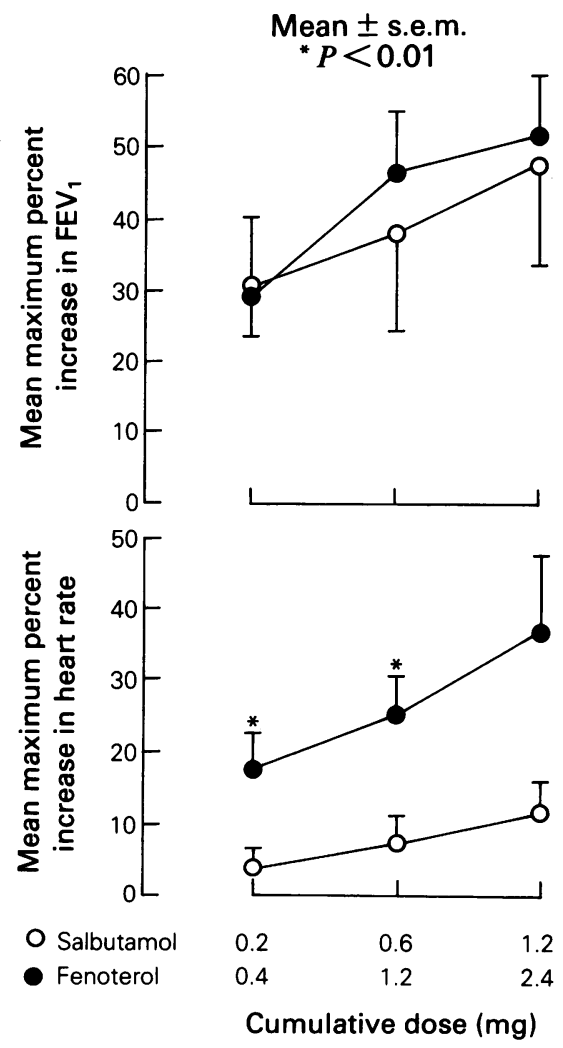

Figure 1 Cumulative dose response curves for salbutamol and fenoterol. FEV, (upper graph) and heart rate (lower graph) are expressed as mean percentage change from baseline values. profound cardiac stimulating action with an absolute increase in mean heart rate of 37 beats/minute above baseline for the highest dosage level. In one 18 year old female, the heart rate rose from 68 to 140 beats/minute following the final dose of fenoterol. The differences in heart rate between the 2 treatments were statistically significant $(P<0.01)$ after both the 2 and 6 puff cumulative doses, but were not significant $(P<0.1)$ at the highest dose.

The reported side effects from patients were palpitations (2), tremor (1) and dizziness (1) after salbutamol; and palpitations (3), tremor (5), dizziness (2) and unpleasant taste (3) after fenoterol. These side effects occurred predominantly at the 12 puff doses.

\section{Discussion}

Our results show that salbutamol and fenoterol are both effective bronchodilators with no significant difference between them puff per puff as regards potency. Fenoterol, however, delivers $200 \mu \mathrm{g}$ per puff as opposed to $100 \mu \mathrm{g}$ of salbutamol and fenoterol produced a greater stimulatory effect on heart rate with, in some cases, considerable tachycardia at high doses. This finding was also noted by Beardshaw et al. ${ }^{2}$ The recommended dose of $400 \mu \mathrm{g}$ fenoterol (2 puffs) produces few side effects as had been observed in other studies. ${ }^{1-3}$ An unpleasant taste and tremor were moré common following fenoterol. Salbutamol would thus avoid tachycardia and seems more selective than fenoterol if higher doses of inhaled bronchodilator are required. Care should also be exercised in prescribing fenoterol inhalers to those asthmatic patients who are known to abuse their use.

The dose response curves for both agents clearly show a greater degree of bronchodilatation with increased dose. A number of authors ${ }^{5-7}$ have suggested that bronchodilatation can be submaximal with a standard dosage of 2 puffs 4 times daily. Corris et al. ${ }^{7}$ have shown that higher doses of salbutamol in patients with chronic obstructive bronchitis can achieve not only greater peak bronchodilatation, but also a more prolonged action. Prior et al. ${ }^{5}$ have demonstrated that high dose inhaled terbutaline (4 $\mathrm{mg} 4$ times/day) can significantly improve both morning and evening levels of peak flow when compared with standard dose therapy. It would thus seem likely that regular higher doses of beta-agonist may provide better overall control of asthma by day and night and our results support the use of up to 6 puffs of salbutamol as a dose suitable for greater effectiveness, but without significant adverse systemic side effects. Just as the dose of theophylline needs to be adjusted to obtain optimum blood levels, a dose response to inhaled beta agonists may help identify the most appropriate dose for individual patients. 


\section{References}

1. Shenfield, G.M. \& Paterson, J.W. Clinical assessment of bronchodilator drugs delivered by aerosol. Thorax 1973, 28: $124-128$.

2. Beardshaw, J., Maclean, L. \& Chan-Yeung, M. Comparison of the bronchodilator and cardiac effects of hydroxyphenylorciprenalin and orciprenaline. Chest 1974, 65: 507-511.

3. Minette, A. Ventilatory results and side effects of salbutamol given by different routes in coal miners with reversible broncho-obstruction. Postgrad Med J 1971, 47 (Suppl, March): 55-61.

4. Gray, B.J., Frame, M.H. \& Costello, J.F. A comparative double blind study of the bronchodilator effects and side effects of inhaled fenoterol and terbutaline administered in equipotent doses. Br J Dis Chest 1982, 76: 341-350.

5. Prior, J.G., Nowell, R.V. \& Cochrane, G.M. High dose terbutaline in the management of chronic severe asthma; comparison of wet nebulisation and tube spacer delivery. Thorax 1982, 37: 300-303.

6. Prior, J.G. \& Cochrane, G.M. Assessment of optimum dose of terbutaline in patients with chronic asthma; the use of simple, cumulative dose-response curves. $\mathrm{Br} \mathrm{J} \mathrm{Dis}$ Chest 1982, 76: 266-268.

7. Corris, P.A., Neville, E., Nariman, S. \& Gibson, G.J. Dose response study of inhaled salbutamol powder in chronic airflow obstruction. Thorax 1983, 38: 292-296. 